\title{
Erratum: RSV-specific airway resident memory CD8 + T cells and differential disease severity after experimental human infection
}

Agnieszka Jozwik, Maximillian S. Habibi, Allan Paras, Jie Zhu, Aleks Guvenel, Jaideep Dhariwal, Mark Almond, Ernie H.C. Wong, Annemarie Sykes, Matthew Maybeno, Jerico Del Rosario, Maria-Belen Trujillo-Torralbo,

Patrick Mallia, John Sidney, Bjoern Peters, Onn Min Kon, Alessandro Sette, Sebastian L. Johnston,

Peter J. Openshaw \& Christopher Chiu

Nature Communications 6:10224 doi: 10.1038/ncomms10224 (2015); Published 21 Dec 2015; Updated 9 Mar 2016

In Fig. 5 of this article, the three dot plots in the first row of panel a contain black numerical labels that are incorrect, and light blue labels that are correct. A revised version of Fig. 5, with correct labels in black throughout, appears below. 
a

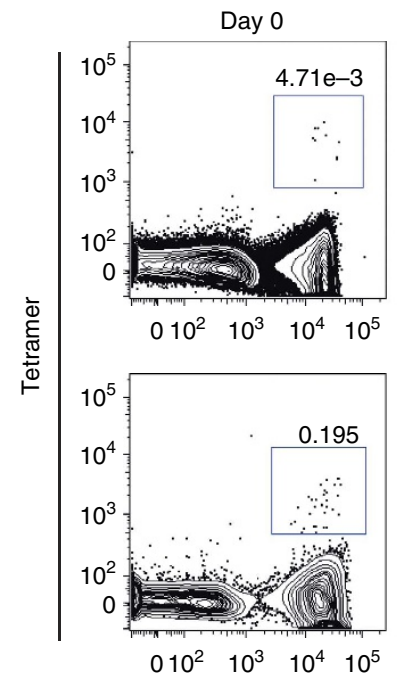

Day 10
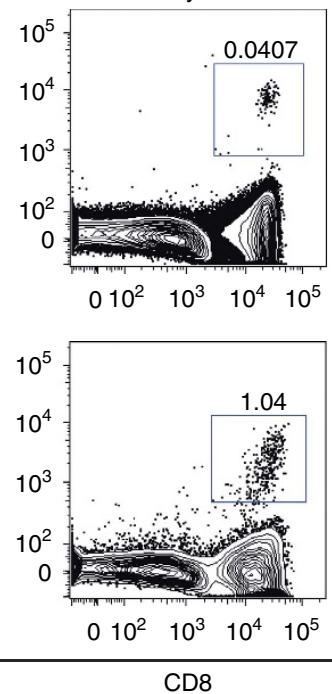

Day 28
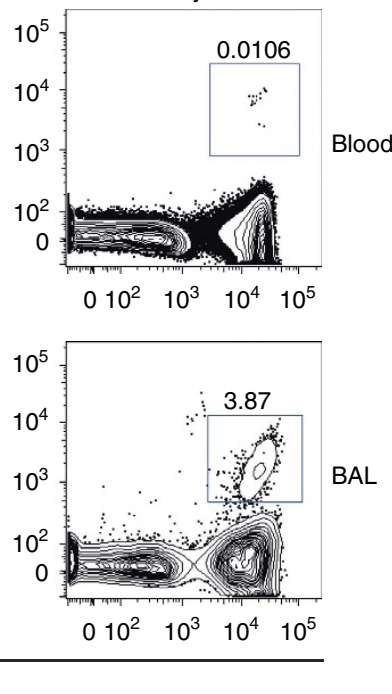

b

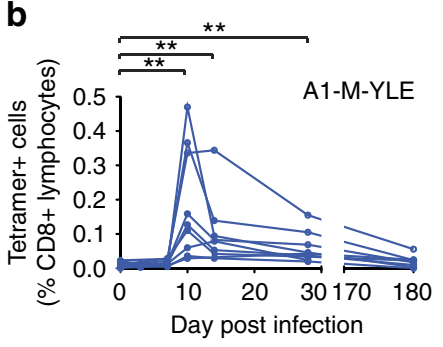

C

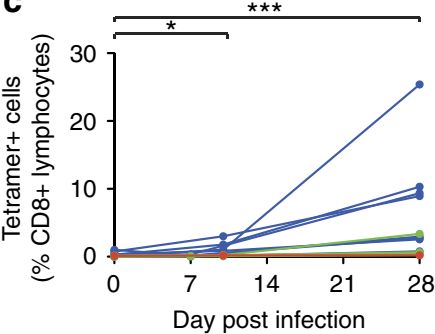

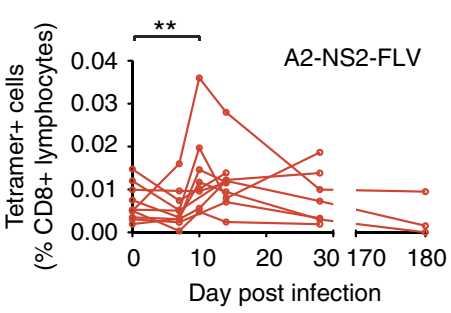

d

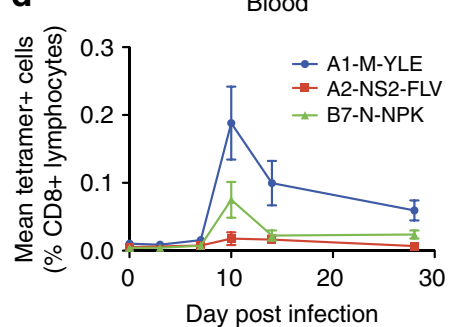

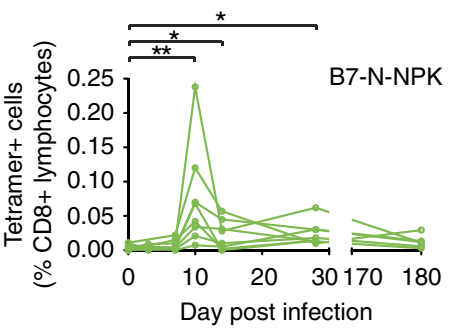

BAL

e

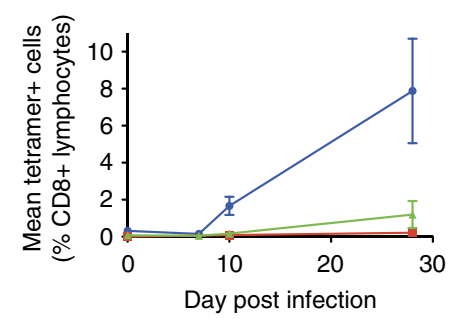

Figure 5

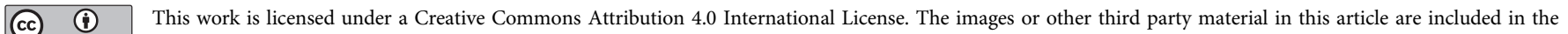
article's Creative Commons license, unless indicated otherwise in the credit line; if the material is not included under the Creative Commons license, users will need to obtain permission from the license holder to reproduce the material. To view a copy of this license, visit http://creativecommons.org/licenses/by/4.0/ 